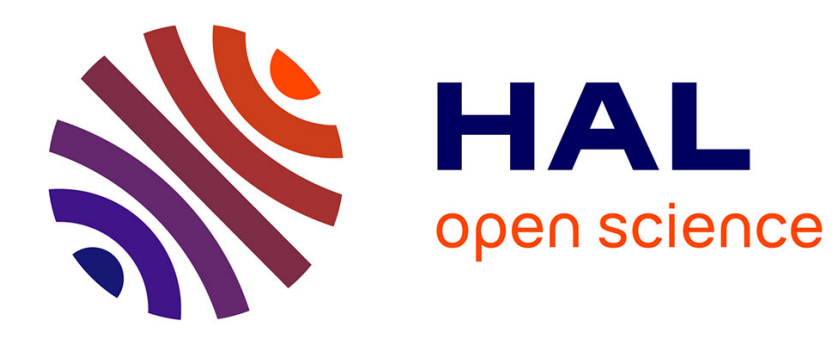

\title{
Anisotropy of small-angle neutron scattering in metallic glasses
}

\author{
A.R. Yavari, M. Maret
}

\section{To cite this version:}

A.R. Yavari, M. Maret. Anisotropy of small-angle neutron scattering in metallic glasses. Journal de Physique Lettres, 1983, 44 (13), pp.553-559. 10.1051/jphyslet:019830044013055300 . jpa-00232231

\section{HAL Id: jpa-00232231 https://hal.science/jpa-00232231}

Submitted on 1 Jan 1983

HAL is a multi-disciplinary open access archive for the deposit and dissemination of scientific research documents, whether they are published or not. The documents may come from teaching and research institutions in France or abroad, or from public or private research centers.
L'archive ouverte pluridisciplinaire HAL, est destinée au dépôt et à la diffusion de documents scientifiques de niveau recherche, publiés ou non, émanant des établissements d'enseignement et de recherche français ou étrangers, des laboratoires publics ou privés. 
Classification

Physics Abstracts

61.40

\title{
Anisotropy of small-angle neutron scattering in metallic glasses (*)
}

\author{
A. R. Yavari, \\ Laboratoire de Thermodynamique et Physico-Chimie Métallurgiques, \\ E.N.S.E.E.G., Domaine Universitaire, B.P. 75, 38402 Saint Martin d'Hères, France
}

and M. Maret

Institut Laue-Langevin, 156 X, Centre de Tri, 38042 Grenoble Cedex, France

(Reçu le 28 février 1983, révisé le 20 avril, accepté le 5 mai 1983)

\begin{abstract}
Résumé. - La diffusion de neutrons aux petits angles (DNPA) dans les verres métalliques est anisotrope et dépend de l'orientation des rubans. L'anisotropie observée dans des rubans amorphes d'un alliage de Pd préparé par " melt-spinning " est différente de celle des plaques d'un alliage de $\mathrm{Ni}$ amorphe préparé par la déposition électrochimique. Les particules à l'origine de la diffusion ont des largeurs de l'ordre de $\mathbf{4 0} \mathrm{nm}$ dans le plan des deux types d'amorphe. Cependant, tandis que les défauts sont très minces suivant l'épaisseur du ruban de melt-spinning, ils sont très longs suivant l'épaisseur des plaques d'amorphes préparées par voie électrochimique. Ces épaisseurs représentent les directions normales aux surfaces du substrat de melt-spinning et de l'électrode de déposition pour les amorphes respectifs.
\end{abstract}

\begin{abstract}
SANS in metallic glasses is anisotropic and depends on the orientation of the ribbons. Pd-based melt-spun and $\mathrm{Ni}$ - based electrochemically deposited glasses exhibit different anisotropies. Both glasses contain scattering centres of the order of $40 \mathrm{~nm}$ wide in the ribbon plane. In the melt-spun alloy, the scatterers are very thin along the thickness perpendicular to the substrate. In the deposited alloy however, the defects are long along the thickness perpendicular to the electrode.
\end{abstract}

\section{Introduction.}

There are several different methods used for the elaboration of films or ribbons of metallic glasses. Examples are melt-spinning and planar-flow-casting (from the liquid state), sputtering, electrochemical deposition and laser beam surface melting. In melt-spinning, the liquid is flattened by the substrate motion perpendicular to the arriving liquid alloy jet. The solidifying liquid layer is therefore sheared while being cooled on the substrate [1]. We have suggested that this shearing action might induce a structural anisotropy in the solidified ribbon [2]. Windsor et al. [3] traced a weak anisotropy in atomic short-range-order by neutron scattering measurements. Since heterogeneities of the order of 1 or $10 \mathrm{~nm}$ have been detected in metallic glasses, we considered

(*) The French version of this paper has been submitted to Comptes Rendus de l'Académie des Sciences. 
it possible that the elaboration method might induce a shape anisotropy and a preferred orientation of these defects [4]. If so, this would be visible in small-angle-neutron-scattering (SANS). Cargill found that small-angle X-ray scattering is anisotropic in sputtered metallic glasses [5].

In this letter we report the detection of different anisotropies by SANS mesurements in two metallic glasses prepared by melt-spinning and electrochemical deposition.

\section{Experimental procedure.}

The amorphous ribbons of $\mathrm{Pd}_{80} \mathrm{Si}_{12} \mathrm{Ge}_{8}$ alloy $25 \mu \mathrm{m}$ thick, $2 \mathrm{~mm}$ wide and $20 \mathrm{~m}$ long were produced on the melt-spinning apparatus of Laboratoire de Thermodynamique et PhysicoChimie Métallurgiques. Part of this ribbon was wrapped around a $12 \times 25 \mathrm{~mm}^{2}$ frame forming parallel layers as in a deck of cards. The average thickness of the ribbon deck across the frame was $0.4 \mathrm{~mm}$. The $\mathrm{Ni}_{80} \mathrm{P}_{20}$ amorphous foils $15 \times 15 \times 0.09 \mathrm{~mm}^{3}$ were produced by electrochemical deposition at the Laboratoire de Physique des dépôts métalliques de l'Université de Nancy. Three foils were stacked to obtain a total thickness of $0.27 \mathrm{~mm}$. Cd windows on the sample holder were arranged to expose $1 \mathrm{~cm}^{2}$ of sample area to the incident beam. The SANS experiments were performed on the D17 spectrometer at ILL, Grenoble. A broad scattering angle $2 \theta$ and scattering vector $Q=4 \pi \sin \theta / \lambda$ range was achieved by using incident neutron beam wavelengths $\lambda=1$ and $1.5 \mathrm{~nm}$ and both the 140 and $282 \mathrm{~cm}$ settings of the sample-detector distance. These settings allow measurement of the scattered intensity $I(\mathbf{Q})$ for $\mathbf{Q}$ values between 0.07 and $2 \mathrm{~nm}^{-1}$. The measured intensities were corrected for background noise, sample absorption and detector response and normalized by vanadium, in order to determine coherent differential cross-section $I(Q)=\mathrm{d} \sigma / \mathrm{d} \Omega$ in barns per atom. The measurements were taken first with the ribbon decks placed parallel to the plane of the multidetector and perpendicular to the incident neutron beam direction along $X$ (Fig. 1). Next the scattered intensity was measured with the decks tilted by an angle $\phi=20^{\circ}$ towards the detector and along the incident beam direction (see $\phi$ in Fig. 1).

\section{Experimental results.}

When the ribbon deck is placed perpendicular to the beam and parallel to the detector plane, any anisotropy in the scattered intensity $I(Q)$, where $Q$ is the scattering vector, is directly revealed on isointensity contour maps traced through detector cells registering equal counts. The detector

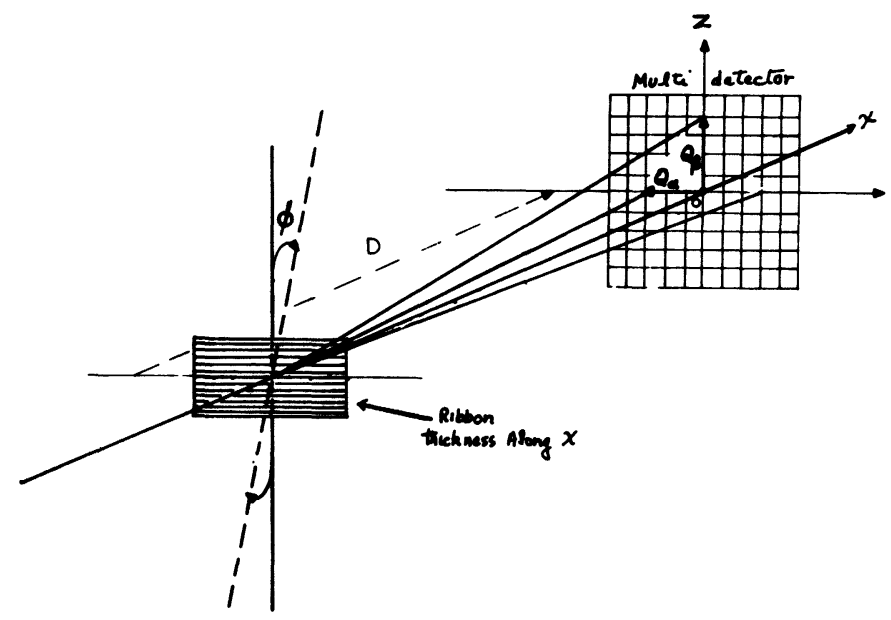

Fig. 1. - Schematic drawing of the sample-detector arrangement on the D17 spectrometer. The ribbons have their thickness along the neutron beam incident along $X$. 
plane corresponds to the plane in Q-space perpendicular to the beam. Figures $2 a$ and $2 b$ show two such sets of contour maps corresponding to the scattered intensity from melt-spun $\mathrm{Pd}_{80} \mathrm{Si}_{12} \mathrm{Ge}_{8}$ and electrochemically deposited $\mathrm{Ni}_{80} \mathrm{P}_{20}$ ribbon decks respectively. In both cases the ribbon's thickness is strictly parallel to the beam. A moderate but distinct anisotropy is visible in the low angle region for the melt-spun Pd based alloy but not for the electro-deposited $\mathrm{Ni}_{80} \mathrm{P}_{20}$. To confirm the spacial relation between the anisotropy of $I(Q)$ and the ribbon orientation, the ribbons stack was next rotated by 90 degrees in-plane while remaining parallel to the multidetector. The isointensity contours of $I(Q)$ also rotated by 90 degrees thus maintaining the initial spacial relation of their axes with those of the ribbons. The contour maps of figure $2 a$ correspond to the ribbon decks perpendicular to the beam with the long-axis $\alpha$ (direction of substrate motion for the melt-spun alloy) placed vertically and corresponding to a 90 degrees rotation around $X$ from the position shown in figure 1 . Figure 3 shows corrected intensity values $I(\mathbf{Q})$ in barns per atom for the melt-spun alloy plotted against scattering vectors $\mathbf{Q}_{\alpha} / / \alpha$ and $\mathbf{Q}_{\beta} / / \beta$ where $\alpha$ and $\beta$ are the ribbon length and width respectively. It is seen that the $I(\mathbf{Q})$ drops faster along $Q_{\alpha} / / \alpha$. The ribbon decks were then tilted by an angle $\phi=20^{\circ}$ from their initial position parallel to the detector (Fig. 1). A very strong anisotropy was found in the contour maps for the $\mathrm{Ni}_{80} \mathrm{P}_{20}$ alloy decks (Fig. $2 c$ ), with the intensity now falling very rapidly along the projection of the ribbon thickness parallel to the multidetector's vertical $Z$-axis. For the melt-spun alloy, the tilt results in a smaller effect but in the opposite direction; with the intensity dropping more slowly along the projection of the thickness along $Z$. Figures $4 a$ and $4 b$ show $I(Q)$ as a function of $Q / / Z$ for the tilted and non-tilted geometries of the melt-spun and electrochemically deposited alloy respectively.

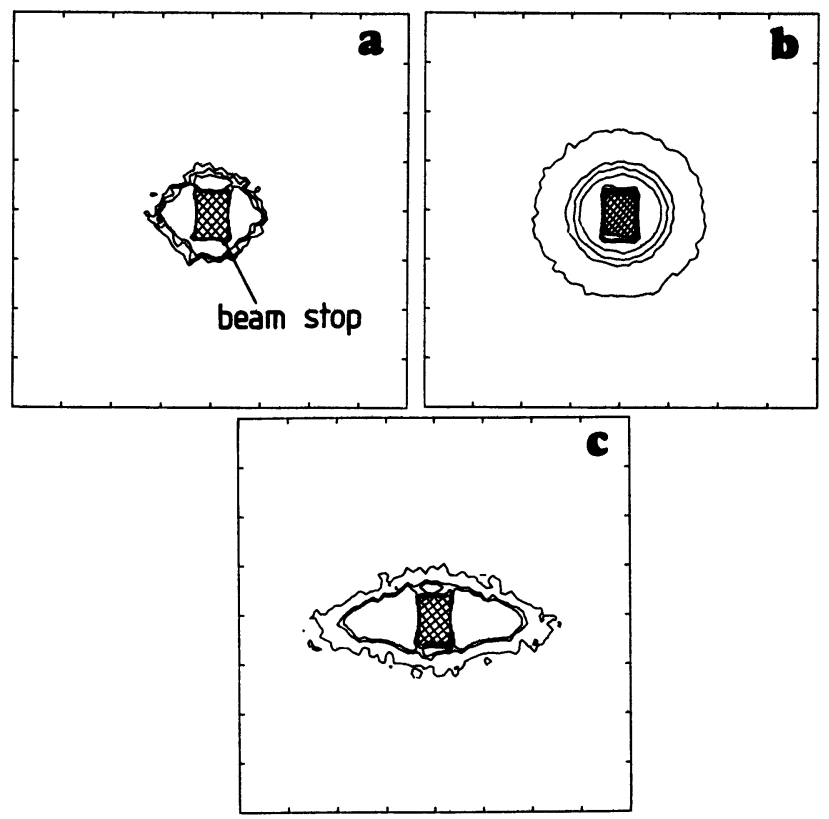

Fig. 2. - Small angle isointensity contour maps. (a) Melt-spun Pd-based glass with the ribbons placed. parallel to the detector with their length in the vertical direction. Electrochemically deposited Ni-based glass with surface $(b)$ parallel and $(c)$ at an angle $\phi$ to the detector plane. 


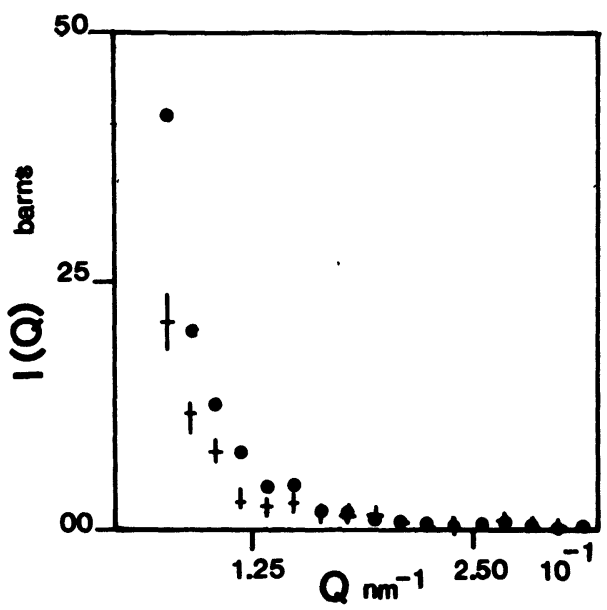

Fig. 3. - Scattered intensity for melt-spun ribbons placed parallel to the detector for scattering vectors $\mathbf{Q}$ parallel to the ribbon length $(+)$ and width $(\bullet)$.

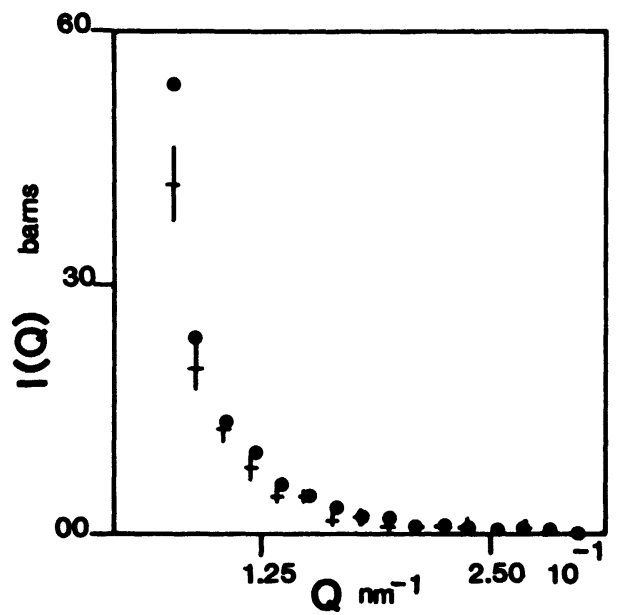

(a)

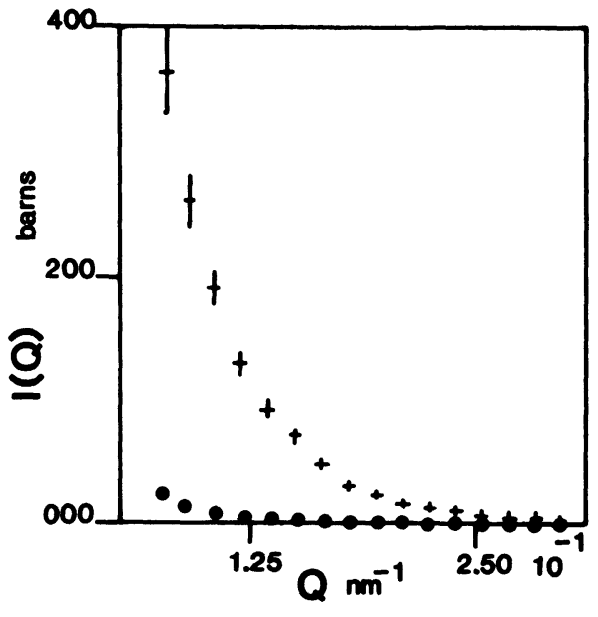

(b)

Fig. 4. - Scattered intensity for the Pd-based melt-spun $(a)$ and electrodeposited Ni-based $(b)$ ribbon decks. Scattering vector $\mathbf{Q}_{\beta}$ in position (+) parallel (+) and $(\bullet)$ at an angle to the detector (see Fig. 1).

\section{Discussion.}

We interpret the observed anisotropy in the scattered intensity in terms of a preferred orientation of scattering defects with a shape anisotropy. Guinier plots of $\ln I(Q)$ as a function of $Q^{2}$ can be constructed from the intensity data of the non-tilted configuration shown in figures 3 and 4.

The slopes of such plots extrapolated to $Q=0$ yield average in-plane radii of gyration $R_{\mathrm{g}}$ of the order of $20 \mathrm{~nm}$ for both the melt-spun Pd-based and electrochemically deposited Ni-based ribbons. However the slopes of the Guinier plots continue to increase slowly at the lowest $Q$ 
values especially for the melt-spun alloy and accurate determination of $\boldsymbol{R}_{\mathrm{g}}$ requires further measurements at smaller scattering angles. Following Guinier and Fournet [6], we take the scattered intensity from a fixed scatterer with a shape anisotropy to fall with increasing $\mathbf{Q}$ according to :

$$
I(\mathbf{Q})=I(0) \exp \left(-Q^{2} R^{2}\right)
$$

where $R$ is the average inertial distance of the particle along $\mathbf{Q}$. The intensity due to scattering by this particle would then fall faster along $\mathbf{Q}$ in that direction in which the particle presents its largest dimension. We further suppose that the scattering from an ensemble of these particles with identical orientations is identical on a relative scale to the mean intensity scattered by one isolated particle. According to (1), the isointensity curves in the $Q$-plane would be such that for $\mathbf{Q}$ parallel to defect axes $R_{1}$ and $R_{2}$ (for example, two axes of an ellipsoid or a disc), one would obtain :

$$
\left|\mathbf{Q}_{1}\right|=\left|\mathbf{Q}_{2}\right|\left(R_{2} / R_{1}\right)
$$

Alternatively at constant $|\mathbf{Q}|$ :

$$
\ln \left\{I\left(\mathbf{Q}_{1}\right) / I\left(\mathbf{Q}_{2}\right)\right\}=Q^{2}\left\{R_{2}^{2}-R_{1}^{2}\right\},
$$

which can be used in conjunction with the approximate relation $\left(R_{1}+R_{2}\right) / 2 \simeq R_{\mathrm{g}} \simeq 20 \mathrm{~nm}$ the average radius of gyration that we referred to previously.

Applying this formulation to the data of figure 3 for the untilted melt-spun alloy, for $\mathbf{Q} / / \alpha$ and $\mathbf{Q} / / \beta$ (the directions of ribbon length and width), we obtain $R_{\alpha} / R_{\beta} \simeq 1.17$. This would mean that the scattering defects are somewhat elongated along the ribbons' long axis which is the direction of substrate motion in melt-spinning. The electrochemically deposited alloy shows no such in-plane defect anisotropy. When the samples are tilted, the scattering vector $\mathbf{Q}$ has a nonzero component along the sample thickness. The measured $R$ for the tilted sample, which we call $R_{\phi}$, should therefore be different from $R_{0}$ in the ribbon plane, unless the defects are as thick as they are wide. Fits of (1) for the data of figures $4 a$ and $4 b$ for tilted and untilted positions of the melt-spun alloy and the electrochemically deposited alloy yield $R_{\phi} / R_{0} \simeq 0.94$ and 2.56 respectively. This indicates that, in the melt-spun alloy, the scattering defects are thinner along the ribbon thickness than in the ribbon plane but that the reverse is true for the deposited alloy.

More quantitative information on the defect dimensions along the ribbon thickness can be obtained from the angular variation of $\boldsymbol{R}_{\phi}$ with $\phi$. Consider a disc or a cylinder with dimensions $a, b$ and $c$ ( $a=b$ for cylinder) and cross-section on the $b-c$ plane as shown in figure 5 . Consider such defect shapes in the sample such that $a, b$ and $c$ are oriented along the ribbon length $\alpha$, width $\beta$ and thickness $\varepsilon$. When the ribbons are tilted by angle $\phi$ (Fig. 1) the projection of the defect into the vertical $Z$-axis will be modified as shown in figure 5 . The $Z$-axis is parallel to the ribbon width $\beta$ or defect width $b$ in the non-tilted sample as well as the vertical axis of the multidetector and $\mathbf{Q}_{\beta}$ as shown in figure 1 . For illustration, we consider discs or cylinders with consequent sharp edges but a similar analysis can be made for other edge-forms. In analogy to figure 5 , the neutron beam scattered by the tilted ribbon will see the $Z$ projection of the defect as its centre to edge distance $R_{\phi}$ along $Z$. $R_{\phi}$ over $R_{0}$ of the untilted position will be given by :

$$
R_{\phi} / R_{0}=b \cos \phi+c \sin \phi .
$$

For $\phi=20^{\circ}$, we obtain :

$$
R_{\phi} / R_{0}=0.94+0.34 \frac{c}{b} \text {. }
$$




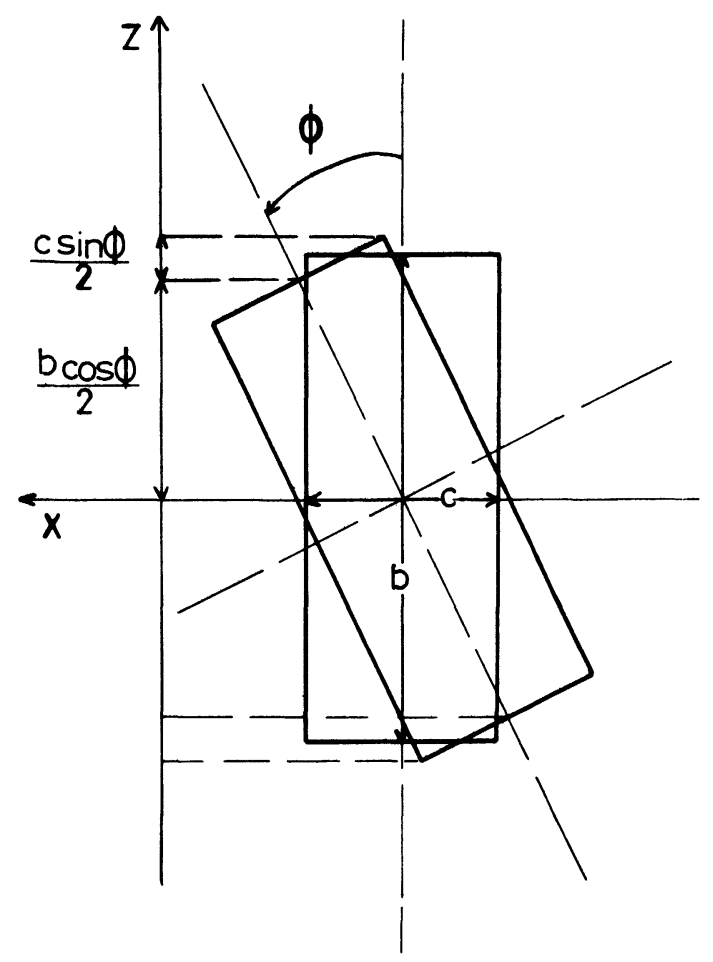

Fig. 5. - Schematic drawing of projection on the $Z$-axis of the cross-section of a defect in the $X-Z$ plane parallel and tilted by $\phi$ with respect to $Z$.

It is seen that for a defect as thick as it is wide $(c=b)$, tilting will result in $R_{\phi} / R_{0}>1$. The ratio $R_{\phi} / R_{0}$ decreases slowly with decreasing $c / b$ and has a minimum of 0.94 at $c \ll b$. Since $\boldsymbol{R}_{\phi} / \boldsymbol{R}_{\mathbf{0}} \simeq 0.94$ for the melt-spun alloy, we conclude that the scattering defects in these ribbons are very thin across the ribbon thickness thus roughly resembling thin discs with their plane parallel to the quenching substrate and slightly elongated along the direction of motion of the melt-spinning roller. With the present experimental accuracy we find a defect dimension along the ribbon thickness between 0 and $3 \mathrm{~nm}$. Our planned experiments at smaller scattering angles will allow a more precise determination of the thickness of the defects.

For the electrochemically deposited alloy we observe $R_{\phi} / R_{0} \simeq 2.56$ which implies that $c / b \gg 1$. From (5), we obtain $c \simeq 5 b$. Using the average in-plane radius of gyration $R_{\mathrm{g}} \simeq 20 \mathrm{~nm}$ for $b$, we obtain a thickness $c \simeq 100 \mathrm{~nm}$. Thus scattering defects in the electrochemically deposited alloy seem to have a columnar structure with the defect long axis across the thickness or perpendicular to the electrode surface, we conclude that metallic glasses prepared by melt-spinning and by electrochemical deposition contain defects with a shape anisotropy and a preferred orientation. The defect shapes and preferred orientations depend on the method of elaboration. Additional SANS experiments are planned to deduce the exact defect shapes and dimensions. Other experiments are planned to determine the nature of the diffusing defects (i.e. concentration fluctuations, density defects etc.). 


\section{Acknowledgments.}

We would like to thank J. Flechon of the Laboratoire de Physique des Dépôts Métalliques, Université de Nancy for providing the $\mathrm{Ni}_{80} \mathrm{P}_{20}$ samples and $\mathrm{D}$. Worcester for help during the experiments. We are grateful to $\mathbf{P}$. Chieux of ILL, for guidance and encouragement and to the ILL for beam time on the D 17 spectrometer. We also thank Noëlle Maitre and Isabelle Moulin for help in the preparation of the manuscripts and acknowledge the help of $M$. Senillou in the preparation of the melt-spun alloy.

\section{References}

[1] Yavari, A. R., Desré, P. and Hicter, P., Scripta Met. 15 (1981) 503.

[2] Yavari, A. R., Hicter, P. and Desré, P., Proc. 4th Int. Conf. on Rapidly Quenched Metals, eds. T. Masumoto and K. Suzuki, Japan Inst. Metal 1 (1981) 713.

[3] Windsor, C. G., Boudreaux, D. S. and Narasimham, M. C., Phys. Lett. 67A (1978) 282.

[4] Yavari, A. R., Proc. 5th Int. Congress on Phys. of Non-cryst. Solids, ed. J. Zarzicki, J. Physique Colloq. 44 (1982) C9-619.

[5] Cargill III, G. S.. Proc. 3rd Int. Conf. on Rapidly Quenched Metals, Brighton 1 (1978) 364.

[6] Guinier, A. and Fournet, G., Small-Angle Scattering of $X$-rays (John Wiley and sons Inc., N. Y.) 1955 , p. 30. 